\title{
A POÉTICA DAS ÁgUAS: UM OLHAR LÍQUIDO SOBRE A POESIA DE PEDRO CASALDÁliga ${ }^{1}$
}

\author{
THE POETICS OF THE WATERS: A LOOK ON THE POETRY OF PEDRO CASALDÁLIGA
}

\author{
Edson Flávio SANTOS \\ Doutor em Estudos Literários (UNEMAT). \\ E-mail: edsonflaviomt@gmail.com
}

Resumo: O objetivo principal desse texto foi colocar em relevo parte da produção de Casaldáliga, a vocação e empenho para com a mensagem poética e, mostrar parte das informações sobre sua luta pela promoção humana, perceber como ele a plasma na e pela poesia tornando-a comprometida não só com o social, mas também com todo o cosmos, pois a construção da história humana jamais se dissocia da natureza. Ao contrário, faz surgir um ser humano que com ela tem estreitas relações. A abordagem foi realizada por meio da análise de poemas, que mostram Pedro Casaldáliga com sua vida permeada e, até certo ponto, banhada pela imagem de rios, e amparada pelas percepções de BACHELARD (1997), BOSI (2002) e CANDIDO (1996).

Palavras-chave: Poética casaldaliana; Rio Araguaia; Missionário.

Abstract: The main objective of this text was to emphasize part of Casaldaliga's production, his vocation and commitment to the poetic message, and to show some of the information about his struggle for human promotion, to perceive how he embodied it in and through poetry, making it compromised not only with the social, but also with the whole cosmos, since the construction of human history never dissociates itself from nature. On the contrary, it brings forth a human being who has close relations with her. The approach was accomplished through the analysis of poems, which show Pedro Casaldáliga with his life permeated and to some extent bathed by the image of rivers, and supported by the perceptions of BACHELARD (1997), BOSI (2002) and CANDIDO (1996).

Keywords: Casaldáliga poetics; Rio Araguaia; Missionary

\section{Introdução}

Tudo o que ali se exibia, afinal, se inventava de existir. Pois, naquele lugar se perdia a fronteira entre água e terra. Aquelas inquietas calmarias, sobre as águas nenufarfalhudas, nós éramos os únicos que preponderávamos.

- Neste lugar não há pedacitos. Todo o tempo, a partir daqui, são eternidades. (Nas águas do Tempo - Mia Couto)

\footnotetext{
${ }^{1}$ Texto retirado da dissertação de mestrado CERCAS MALDITAS: utopia e rebeldia na obra de Dom Pedro Casaldáliga, sob orientação da Prof. Dra. Olga Maria Castrillon-Mendes e serviu de base para novos estudos sobre o autor na confecção da tese de doutorado ESPERANÇA E LIBERTAÇÃO: interfaces de uma utopia na/pela poesia de Agostinho Neto e Pedro Casaldáliga sob orientação do Prof. Dr. Benjamim Abdala Júnior e coorientação da Profa. Dra. Vera Maquêa.
} 
Em 1968, Casaldáliga e outro claretiano chegam à região do Araguaia e, nas palavras de Casaldáliga, esse fato toma uma força histórica: "chegavámos a um mundo sem retorno" (1979, p. 30), presentificando imageticamente o dizer estratificado pelo discurso corrente. Iniciava-se a permanência desse autor em solo de Mato Grosso, lugar que seria escolhido para viver, fato esse impresso em um poema que, pelo número de versos em suas estrofes, assemalha-se a um soneto "Testamento" (1978, p. 205), aos moldes iniciais do modernista Mário de Andrade:

Enterrem-me no rio, perto de uma garça branca. O resto já será meu.

E aquela correnteza franca

que eu, passando, pedia, será pátria recuperada. O êxito do fracasso. A graça da chegada.

A sombra-em-cruz da vida, sob este sol de verdade tem a exata medida

da paz de um homem morto... E o tempo é eternidade e toda a rota é porto!

Casaldáliga escolhe para esses versos a forma do soneto, na apresentação de 4 estrofes de métricas diferenciadas, dois quartetos e dois tercetos, revigorando a métrica clássica, mas sem se apegar a ela.

O desejo de encerrar a vida no Araguaia é o desejo de se fazer um só ser com o Rio Araguaia, de servir de adubo, de vida, uma vez que deu a vida em vida, agora o desejo de dar a vida com a própria morte. A imagem da morte vai também acompanhar o autor ao longo da produção poética, seja pelas ameaças de morte que sofreu, seja pela morte de tantos que presenciou ao longo da trajetória de vida. Por isso, o pedido que abre o poema: "Enterrem-me no rio,".

De acordo com Eliade (1979, p. 148), "tanto no plano cosmológico como no plano antropológico, a imersão nas águas equivale, não a uma extinção definitiva, mas a uma reintegração passageira no indistinto, seguida de uma nova criação, de uma nova vida ou de um homem novo".

O autor sabe, pelo viés da formação religiosa, que a vida gasta (aqui) na terra na luta 
pela vida dos irmãos é vida ganha no céu. E o fracasso dessa vida aqui está apenas no corpo que perde a força vital, mas só isso, pois a nova vida, numa nova criação, vence a morte terrena. A aproximação com a morte sempre esteve presente, e sua sombra é a exata medida do tamanho necessário para o descanso do corpo. Por isso, a sombra projetada no solo deixa registrado o tamanho do lugar onde repousará o homem morto.

Há nesse texto imagens bem construídas que se explicam no próprio poema e outras que lançam para a compreensão fora do soneto. A imagem da garça branca é, por várias vezes, recorrente na poética casaldaliana, merecendo, inclusive, poemas dedicados a essa ave.

Essa ave, de pernas finas, corpo miúdo, bico em riste e olhos pequenos, comum nas beiras dos rios de Mato Grosso, por vezes solitária, atravessa o texto. É a lembrança da paz que vem pela cor branca e a imagem do silêncio, da reclusão da hora da morte. Como alguém que vela o túmulo, ou assiste ao seu enterro, Dom Pedro quer estar perto da ave que não faz estardalhaço como as outras, mas é silenciosa como ele é no momento da dor.

A imagem do silêncio que abre o poema, "Enterrem-me no rio, perto de uma garça branca", (CASALDÁLIGA, 1978, p. 205), é retomada pelo sinal de reticências posto no primeiro verso da última estrofe,
A sombra-em-cruz da vida, sob este sol de verdade tem a exata medida
da paz de um homem morto... E o tempo é eternidade e toda a rota é porto! (idem)

"A graça da chegada" contrasta com a garça branca presente na hora da partida. O jogo do anagrama garça/graça é a retomada dos sentidos: silêncio da partida, alegria na chegada, corroborado por outro verso antagônico "O êxito do fracasso".

Ora, como pode coexistir tal paradoxo? Existe êxito no fracasso? Para Casaldáliga, sim. No poema, o êxito é ter morrido para a vida terrena e nascer para a vida espiritual, pois "toda rota é porto!", uma vez que o importante é estar a caminho, não se acomodar.

Esse desejo de encerrar a vida no ambiente aquático é, segundo Bachelard (1997, p.77), a morte verdadeira, pois: "só se parte bem, corajosamente, nitidamente, quando se segue o fluir da água, a corrente do largo rio. Todos os rios desembocam no Rio dos mortos. Apenas essa morte é fabulosa. Apenas essa partida é uma aventura", nos versos de Casaldáliga: "E o tempo é eternidade e toda a rota é porto! (1978, p. 205)”.

Os versos nutrem a expectativa da conhecida "viagem", muito clara na passagem do 
soneto que diz: "que eu, passando pedia," uma travessia pela terra que também enfrenta o fogo, imagem do sofrimento, aqui no poema representado pela expressão "sob este sol de verdade".

Se "toda a rota é porto!", existem muitos rios a serem navegados, atravessados, conhecidos, vividos e na identificação com a vida do povo e com a região, Casaldáliga declara no poema "Nossas vidas são os $\operatorname{rios}^{2}$..."

Nossas vidas são os rios.

Minha vida é este Araguaia!

Indescritível,

indecifrável.

Que se ama e se agradece, e se teme e deseja;

ao qual se volta sempre,

como a um lar, fatídico e feliz.

Exuberante e cruel,

maravilhosa,

a multiforme fauna,

presente ainda, condenada ao extermínio.

Os jacarés espichados, que atenazam o sol,

As placas insidiosas das arraias.

As piranhas que serram carne viva.

E os peixes elétricos,

estalando a morte.

E os peixes de todos os tamanhos e luzes,

vorazes ou pacíficos.

miúdos,

brincalhões,

voadores.

Os peixes que dão vida,

holocausto à brasa e à pimenta.

Os pássaros, vestidos a rigor,

senhores,

diplomatas.

Essa fileira de patos colegiais,

que espera por um ônibus ali na margem...

E, de súbito, o pulsar

frágil de uma canoa.

E as nuvens, acima, cansadas e fecundas.

As famílias que chegam, retirantes;

os enfermos que vão à deriva;

as cargas, e as cartas trêmulas;

as mulheres batendo a trouxa indiscreta;

os homens na popa, os homens no remo;

e os meninos banhando-se,

somando-se às águas, como peixes.

$\mathrm{E} \mathrm{eu,} \mathrm{pela} \mathrm{manhã,} \mathrm{lavando-me} \mathrm{do} \mathrm{sono}$

como o espelho incandescente ao sol da outra margem;

\footnotetext{
${ }^{2}$ Poema publicado em todas as antologias utilizadas para esse estudo: Antologia Retirante (1978), Águas do Tempo
} (1989) e Versos Adversos (2006). 
eu, pela tarde, entrando, reverente, estrangeiro, vestido pela luz poente e pura na liturgia destas grandes águas... (CASALDÁLIGA, 1978, p 27-29).

O título do poema de quarenta e cinco versos, divididos em três partes, ou estrofes, inicia-se pela metáfora que vai permear boa parte da poesia: Vida / Rio. Essa metáfora se deve ao fato do encantamento pelo grande Rio Araguaia, fato que persiste em vários momentos da produção, assumindo fortemente a proposta dessa figura de linguagem, pois, segundo Hedwig Konrad (1958), "por isso ela é muito mais radical do que a imagem, pois suprime o elemento comparativo e transfunde o sentido de uma palavra na outra" (apud Candido, 1996, p. 87). Com isso, Dom Pedro abre o grande leque das apropriações que a palavra rio traz, ou seja, insere-se na interpretação da vida como um rio.

Aqui e sempre presente o Rio Araguaia que dá nome à região e que também é o rumo, o norte de todo um povo. Símbolo também da resistência, da libertação e da terra prometida; um mar interno e que recorta as divisas do Estado - sereno, quieto, presente.

"Nossas vidas são os rios... (1978, p 27)”, um título seguido de reticência rompe a oração a fim de obter o efeito de movimento do sentido que a frase propõe, pondo à vista do leitor o destaque para que ele mesmo possa perceber que sua vida é como a vida de um rio. Em outras palavras, assim como um rio nasce de um olho d'água e vai crescendo, na medida em que cresce, recebe água de seus afluentes ou deságua em rios maiores, mas sempre corre para o mar. É a representação do caminho de nossa vida.

No poema em estudo, Casaldáliga compara sua vida não a um rio qualquer, mas ao Rio Araguaia: "Minha vida é este Araguaia! Indescritível, indecifrável, (1978, p 27)”.

Considerado um dos maiores rios do Brasil, o Araguaia é a espinha dorsal da região. É não só a referência do sustento, mas também a referência mítica para o surgimento e nomeação do local que designa origem do povo, principalmente, o Karajá.

Por isso, Casaldáliga, ao comparar a vida ao rio, constrói uma das metáforas mais felizes de sua poesia, que sustenta a ideia de engajamento social e poético de que se está tratando aqui. Tal identificação explicita certo compromisso sociocultural e ambiental que se explica pelo uso da poesia como instrumento de defesa do povo e do seu habitat contra todo tipo de exploração que advenha sobre eles. Assim, faz uma opção radical, fato esse bem marcado a partir de gestos externos que a poesia corrobora.

\section{Aliança e compromisso com as causas sociais}

Dom Pedro, por ocasião de sua sagração episcopal, não usou o anel de ouro a que tinha 
direito, mas de tucum, símbolo do compromisso com os pobres e oprimidos, objeto muito utilizado pelos que seguem a teologia da libertação. Juntamente com o anel, adotou, como báculo e mitra, o chapéu sertanejo e o remo-borduna, símbolos da região feitos pelos índios Tapirapé, unindo-se em gestos e símbolos ao povo e à região. Quando chega ao Araguaia, em específico, mesmo depois de ter passado por um período de adaptação no Rio de Janeiro, chega/adentra o nordeste de Mato Grosso sem imaginar o contraste desse novo lugar com a realidade europeia a que estava acostumado.

E, por isso, a característica do estranho-estrangeiro-europeu chama atenção ao final do poema: “eu, pela tarde, entrando, reverente, estrangeiro," (1978, p 29).

O poeta adentra o nordeste do Estado "sem saber sequer quem habitava a região onde as distâncias de toda espécie justificavam todas as indecisões", assim, descobre o Rio Araguaia: "Indescritível, indecifrável, (1978, p 27).

Indescritível, porque as imagens não são suficientes, porque o alcance das imagens supera sua capacidade de verbalização. O rio quieto, assim como Pedro, sempre quieto, não fala de si, nem por si. Indecifrável, que não se lê, que não se advinha, que não se decifra, não se dá pela ausência de significados, mas pela multiplicidade de sentidos que ambos, rio e autor, possuem.

Utilizando-se da construção de um polissíndeto, o poeta descreve o Araguaia como um rio, "Que se ama e se agradece, e se teme e deseja; ao qual se volta sempre, como a um lar, fatídico e feliz, (1978, p 27).

É toda a simbologia do fluxo aquático na simbologia da vida, ou o seu contrário. Da vida que vive dentro do rio. A água do grande rio que nasce e morre no mar, volta a ser rio pelas gotas translúcidas das chuvas, a mesma água que transborda, na cheia que se teme, e leva a vida, que se deseja, encharcando as beiras, adubando o chão e trazendo consigo de volta um pouco das terras que levam o mesmo nome do rio e que se misturam nas águas e inicia novamente todo o processo vital, "ao qual se volta sempre, como a um lar, fatídico e feliz, (1978, p 27).

Um lar que é também o lar de Casaldáliga, onde vive o martírio, tal como vive o júbilo, percebendo o mundo por meio da imagem do rio como num espelho, o grande sol refletido; e declara: "E eu, pela manhã, lavando-me do sono como o espelho incandescente ao sol da outra margem; (1978, p 29).

O eu-lírico se levanta e, no gesto rotineiro, lava o rosto. A imagem da expressão "lavando-me do sono" carrega o sentido de deixar o que passou para traz e assumir o novo dia que nasce com a esperança de alcançar a outra margem, pela travessia do rio. 
Segundo Chevalier "el río simboliza la existencia humana y su flujo, con la sucesión de los deseos, de los sentimientos, e las intenciones" (CHEVALIER, 1986, p. 885) e atravessar esse rio, seria a transformação. No entanto, Casaldáliga não faz a travessia, mas quando se lava do sono e seus olhos encontram o sol incandescente na outra margem que pode ser lida como a transcendência, a perfeição da própria vida. Uma transcendência necessária para a região e que está no reflexo do sol que brilha sobre todos aqueles que habitam aquele Araguaia. O poeta tem, sobretudo, a realidade de sua idealidade. Pela acumulação de elementos da natureza, do povo, do cotidiano, de dentro do poema, surge a imensidão do rio e da região com todos os seres vivos dispersos harmoniosamente na "maravilhosa/a multiforme fauna".

Vistos desse modo, os poemas de Casaldáliga são espelhos de uma região, de uma realidade, de um povo. Assim, na perspectiva do devaneio de Bachelard: "Parece que os objetos carecem da vontade de refletir-se. Restam então "o céu e as nuvens, que têm necessidade de todo o lago para pintar o seu drama" (BACHELARD, 1997. p. 28). E tais nuvens "acima/cansadas e fecundas" também se espelham no poema ao tempo que se espelham nas "grandes águas".

Porém, mesmo na perspectiva de engajamento com a natureza e nos momentos de maior fruição como apresentado no poema, Pedro Casaldáliga não abre mão daquilo que é: militante, revolucionário. Posicionamento percebido pelo campo semântico expresso pelas palavras: teme, cruel, extermínio, atenazam, carne viva, morte, vorazes, holocausto, à brasa.

Abrindo ainda mais o poema, nessa relação natureza x homem, natureza x natureza, existe, em se tratando de um homem religioso, uma dualidade latente, terra x céu. Dessa vez, quem interage nesse dualismo inseparável são os animais:

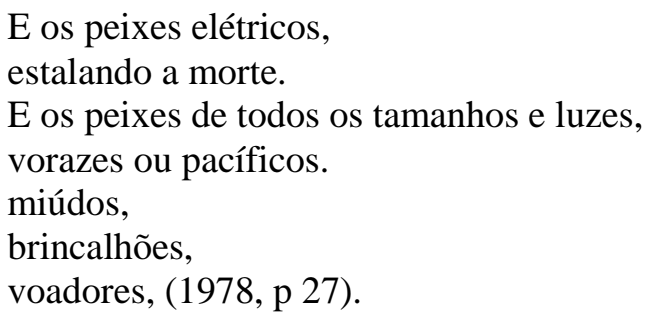

Uma vez nomeados, refletindo a completude da natureza, os seres, recebem o Fiat, do Latim "faça-se", de seu autor e passam a povoar sua obra poética. No trecho acima, por meio da personificação, os peixes elétricos assumem adjetivos que podem também ser dedicados aos homens: vorazes, pacíficos, brincalhões.

Casaldáliga, ao dedicar especial atenção aos seres que habitam o Araguaia, acredita na comunhão universal de toda a terra: "Assim a água torna-se uma espécie de pátria universal; 
ela povoa o céu com seus peixes. Uma simbiose das imagens entrega o pássaro à água profunda e o peixe ao firmamento" (BACHELARD, 1997, p. 54).

Tem-se, assim, o que segundo Maquêa (2012), pode ser chamado de ecovisão, que seria o momento em que o poeta está buscando uma superação da divisão entre homem e natureza, homem e homem, numa espécie de transcendência do humanismo que tem o homem como centro de tudo. Assim, o homem entra de fato em harmonia com a natureza, com os animais, operando por meio dos versos, também, uma espécie de transcendência poética, na qual a poesia está tomada por ela mesma e a linguagem utilizada pelo autor parece estar encantada pela sua própria literalidade.

Esse modo de estar no mundo, de estar nas coisas do mundo, revelado pela ecovisão traz o sentimento de pertencimento e entrelaçamento entre homem e natureza que pode contribuir também para as mudanças nos modos de vida do homem para com a natureza proporcionando um engajamento, visto aqui como o do respeito e valorização da natureza com outros seres e elementos constitutivos dessa ecovisão. Casaldáliga fala de dentro das coisas, como se fosse parte ou a coisa toda, como uma espécie de mimetismo posto na junção dos termos Eu-água, eu-peixe, eu-coisa, eu-rio. É a imagem da comunhão total, expressa, agora, em outro poema emblemático, "Eu e tu, Araguaia” (2006, p. 73)³:

$\mathrm{Eu}$

e tu, Araguaia,

somos um tempo só.

Abraamicamente numerosas

nos garantem os sonhos

as estrelas, lá fora proibidas.

O ipê batiza ainda com outros gratuitos

o silêncio

que nós, ô Araguaia,

conseguimos salvar dos invasores...

Sempre ainda encontramos, eu e tu, a pergunta inquietante de uma garça, na beira, provocando respostas, acordando o mistério...

De acordo com a lua, sacerdotisa virgem, tu estavas, no princípio,

alfombrando as cadências do Aruanã sagrado.

Os potes karajá recolhiam teus olhos desleídos e os peixes costuravam de prata teu banzeiro.

\footnotetext{
${ }^{3}$ Embora o poema encontra-se também na edição de Águas do tempo (1989), optamos por usar apenas a versão cunhada em Versos adversos (2006), pois as versões apresentadas pelas duas edições são diferentes.
} 


\section{Ainda o Padim Ciço \\ não mostrava aos pobres nordestinos \\ essa Bandeira Verde \\ inconquistável...}

Não havia Funai,

Sudam,

nem Incra.

Eram

Deus

e as aldeias.

Impossível fugir da identificação entre o autor e o Rio Araguaia, pois já no enunciado do poema, na forma da junção dos pronomes "Eu e Tu", um sendo Pedro, o autor e o outro, o Rio, ambos formam uma só coisa "Araguaia”.

"Eu e tu, Araguaia, somos um tempo só, (2006, p. 73)", e novamente se estabelece o conceito de ecovisão, pois o poeta entra numa união cósmica, entre si, a terra e a divindade expressa na imagem do rio. Se, no reino da imaginação material, toda união é casamento, então Casaldáliga se casa, no sentido de se unir ao rio literalmente, formando um único ser. Assim, o poema dá conta de expressar o presente que se volta num passado que existiu na busca de um futuro que se quer de volta, pois o passado de nossa alma é uma água profunda (Cf. BACHELARD, 1997, p. 55).

A natureza, simbolizada aqui pela árvore do Ipê, que, além da alegria das cores, oferece o silêncio de quem acompanha tudo: "O ipê batiza ainda com outros gratuitos, o silêncio que nós, ô Araguaia, conseguimos salvar dos invasores... (2006, p. 73)””.

A cumplicidade entre o poeta e o rio se manifesta como um retorno primitivo por assim dizer, que acontece quase dentro de um sonho, de onde surgem imagens míticas que conectadas constroem um cenário de memórias: "De acordo com a lua, sacerdotisa virgem, tu estavas, no princípio, alfombrando as cadências do Aruanã sagrado (2006, p. 73)”.

Tem-se aqui o mito presente no poema, a lua, "sacerdotisa virgem", relatando ao poeta a presença do Rio Araguaia que participa, até hoje, da atividade mítica e mística dessas terras, do ritual do Aruanã. Assim, a poesia visita o espaço sagrado indígena dos Karajá, lembrados nos versos não apenas pelos seus mitos, mas também pelos seus ritos: "Os potes karajá recolhiam teus olhos desleídos, (2006, p. 73)”. 
A arte cerâmica dos povos que habitam o espaço mítico e real da região é reconhecida mundialmente pela categoria própria, por serem produzidas apenas pelas mulheres e pela variedade de motivos que apresentam.

A aproximação de imagens, que o poema suscita, é de tal modo poética que se movimenta como um filme diante do leitor. A noite enegrece as águas do rio e assim a lua quando refletida nas águas do Rio Araguaia, fica espelhada nele da maneira que, quem olhar para o rio enxerga a lua, que mais nos parece um olho.

Dessa forma, os índios Karajá, ao "recolherem" água do rio, recolhem junto esses olhos do rio que vão se "diluir" na movimentação da água dentro dos potes, simetricamente redondos como as órbitas do olho. Eis uma imagem poética muito bem construída. Pois o autor poderia simplesmente dizer que "Os potes karajá recolhiam tuas águas", mas o efeito perderia a poeticidade que está justamente em atribuir vida e aproximação ao Rio Araguaia que espreita tudo e a todos: "estavas, no princípio/alfombrando as cadências do Aruanã sagrado".

O poema que segue uma ordem de revisitação é o retorno ao passado da região que chega ao seu ápice descrevendo o éden que já existiu no Araguaia, o início de tudo: "Não havia Funai, Sudam, nem Incra. Eram Deus e as aldeias, (CASALDÁLIGA, p. 73)”.

É possível ouvir o silêncio deste “éden”, graças ao efeito do recurso estético que o poeta utiliza ao inserir uma pausa no verso e retomá-lo com o sinal de reticências no final das estrofes, como nos versos seguintes

O ipê batiza ainda com outros gratuitos o silêncio que nós, ô Araguaia, conseguimos salvar dos invasores...

Sempre ainda encontramos, eu e tu, a pergunta inquietante de uma garça, na beira, provocando respostas, acordando o mistério... (CASALDÁLIGA, 2006, p. $73)$.

Embora almejando, o poeta já não habita o paraíso descrito, mas, pela poesia e pela revelação de quem viu tudo, nesse momento encontra a idade do ouro, pois "imagina um tempo que nunca existiu a não ser nas dobras de um desejo coletivo de felicidade. Eram saudades do futuro as que ditavam as suas esperanças" (BOSI, 2002, p. 56).

Esse tempo bom, essa idade do ouro, era de paz absoluta, pois a região não tinha as instituições que, na visão crítica e rebelde do poeta, trouxeram, de certa forma, o caos e, na tentativa de "organizar", desorganizaram tudo, mas que é possível, pela poesia, a reconstrução 
de um novo lugar. Um novo lugar de harmonia e abundância, como representado no poema "As Chuvas" (1978, p. 53):

Chegam, por fim, as chuvas.

Chora o deus das chuvas aqui também, talvez.

Leitosidade total, escurecida luz, sem hora alguma, sem horizonte; rio, terra e céu fundidos em um halo.

Com gaivotas ainda, desparafusando-se sobre as praias de água, que o rio abre em seus seios para acolher o vento cúmplice.

A chuva bate, chia e chapinha na água, na terra, nos telhados, nas árvores apenas suspeitadas.

Chove chuva na chuva, Torna a chover, um dia e outro dia. Hoje é a orchata cósmica. Passa um homem molhado, como um mito. Lavam roupa na chuva, as mulheres, com as roupas vestidas, lavando-se no rio e na chuva.

Um cavalo, assustado, sem destino _cinzas empanadas olha não sabe onde, nem sabe bem o que espera, É carne do sertão: está molhando-se, Impotente e anônimo...

Entre o cruzeiro seco e a verde mangueira exuberante, levanta uma árvore em flor, toda só flor, a bandeja carmim de sua alegria.

Piam os pardais no ninho de casa que alugaram sem recibo e sem licença.

Chove. Torna a chover. Continua chovendo.

Será dia ainda?

Chove tão manso agora que se empapam as coisas, com a alma, de uma graça de Deus, feita batismo agreste.

Três barcos, na água e na areia, como sapatos velhos, se molham tão submissos.

E o céu, como um mármore.

Chove, 
Chove...

Esta chuva,

que chega,

de súbito,

como um trem desconhecido,

invadindo tudo loucamente!

Como o maná ${ }^{4}$ caído do céu, as chuvas são "Símbolo de la dualidad de lo alto y lo bajo: aguas de lluvia, aguas de los mares. La primera es pura, la segunda salada. Símbolo de vida: pura, es creadora y purificadora" (CHEVALIER, 1986, p. 56) fundindo céu, terra e rio num "halo".

É possível ainda lembrar do mito épico que é a fecundação da princesa grega Dánae, que, tendo sido presa por seu pai numa torre de bronze, foi alvo do amor de Zeus que se transformou em chuva de ouro e, entrando pelas frestas da torre de bronze, fecundou a princesa que deu à luz a Perseu.

Nessa visão alegórica, instaura-se o mito da terra seca que almeja por água, tem sede de vida, deseja ser fecundada. Daí surge o simbolismo de que a chuva é considerada como esperma, que também tem a função de fecundar.

A simbologia da fecundação e vida está presente no poema por meio das expressões: "orchata cósmica" e "batismo agreste". A ideia dessa união fecunda entre céu e terra está proposta na leitura das duas estrofes que seguem:

Leitosidade total, escurecida luz, sem hora alguma, sem horizonte; rio, terra e céu fundidos em um halo.

Com gaivotas ainda, desparafusando-se sobre as praias de água, que o rio abre em seus seios para acolher o vento cúmplice, (CASALDÁLIGA, 1978, p. 53).

Nota-se aqui um profundo simbolismo de abertura da terra, para receber o céu que a fecunda. A ideia de um só corpo descrito na primeira estrofe pelo verbo fundir vai clarear a interpretação da terra, na imagem do rio que "abre em seus seios para acolher o vento cúmplice", o vento aqui é a personificação do toque divino, aquele que beija a face da terra, que sopra sobre ela, que acaricia, que anuncia o momento da fecundação, é toda uma mística do acasalamento cósmico entre terra e céu, pois:

são precisamente os objetos incessantemente contemplados pelo devaneio hídrico que pressionam a água oculta no céu. Os sinais precursores da chuva

\footnotetext{
${ }^{4}$ Comida de origem divina que o povo hebreu, escravo no Egito, recebia de Deus e que caía do céu para ser consumida naquele dia.
} 
despertam um devaneio especial, um devaneio muito vegetal, que vive realmente o desejo da pradaria pela chuva benfazeja. Em certas horas, o ser humano é uma planta que deseja a água do céu, (BACHELARD, 1997, p. $161)$.

Postas essas reflexões, encontram-se referências desse desejo de água "Chegam, por fim, as chuvas, (1978, p. 53).

A expressão "por fim" tem todo seu motivo, pois a região do Araguaia experimenta, anualmente, duas estações bem distintas: chuva e seca. A seca de abril a setembro e a chuva de outubro a março, na qual se experimenta essa descrição:

Chove chuva na chuva,

Torna a chover, um dia e outro dia.

Hoje é a orchata cósmica.

Passa um homem molhado, como um mito.

Lavam roupa na chuva, as mulheres,

com as roupas vestidas,

lavando-se no rio e na chuva, (CASALDÁLIGA, 1978, p. 53).

Um desejo sem alarde como a chuva, uma chuva que não incomoda, mas que é incorporada no dia a dia. Sem romper-lhe o ciclo da rotina, os homens e as mulheres continuam seus labores, enquanto, numa pausa da chuva, a natureza festeja e nos brinda com sua beleza:

Entre o cruzeiro seco e a verde mangueira exuberante, levanta uma árvore em flor, toda só flor, a bandeja carmim de sua alegria.

Piam os pardais

no ninho de casa que alugaram sem recibo e sem licença, (1978, p. 53).

Embora a chuva invada tudo loucamente, não há insanidade, não há desespero. O poema se acalma na lembrança caseira dos sapatos deixados ao alpendre da casa, como na permissão de pedir entrada, simbolizados aqui pelos barcos deixados metade na água, metade na areia, mostrando que seres do reino das águas vieram nos visitar "submissos" e então uma paz profunda invade os versos: "Chove tão manso agora/que se empapam as coisas, com a alma/ de uma graça de Deus, feita batismo agreste, (1978, p. 55).

O poema é todo água, é todo chuva. As palavras chora, chuva, leitosidade, praias, rio, seios, orchata, lavam, batismo, molham, empapam direcionam o leitor para o sentido líquido dos versos.

As cores, como as do "céu como um mármore", saltam do poema e dão conta de montar uma paisagem de chuva que tem inclusive seus sons, apresentados pela aliteração, na 
sonoridade das consoantes fricativas palatais [ch] e pelas sibilantes alveolares [s], "A chuva bate, chia e chapinha/na água, na terra, nos telhados/nas árvores apenas suspeitadas. (1978, p. $53)$.

O pleonasmo que parece reverberar pelo poema "Chove chuva na chuva" encontra seu eco no recurso da anominação, em "Chove. Torna a chover. Continua chovendo." e, o poema segue assim, em gradação num continuum, até a última estrofe que anuncia, pela reiteração, mais chuva e mais chuva:

Chove,

Chove...

Esta chuva,

que chega,

de súbito,

como um trem desconhecido,

invadindo tudo loucamente! (1978, p. 55).

Em “Junto ao vosso canto" (2006, p. 19), Casaldáliga expressa um desejo de estar cada vez mais próximo do povo, numa atitude que pode parecer passiva, mas que se revela ativa:

Meu silêncio seja meu poema, irmãos, junto ao vosso canto.

Seja minha ausência como um vôo de garças abraçando a tarde, nesse voo de garças que invadiu o dia com o vosso canto.

Velhos de esperança _ tantas luas cheias, Tantas noites foscas eu e o Araguaia já nos conhecemos, rios de um só rio ajeitando o curso entre Deus e o Povo.

Junto ao vosso canto, boca coletiva, seja meu silêncio posto de joelhos uma escuta nova.

Quero ouvir o Povo!

Quero ouvir o grito 


\author{
das crianças mortas \\ comandando a vida. \\ Quero ouvir as covas \\ dos peões do trecho \\ soletrando vivos \\ os perdidos nomes. \\ Quero ouvir os pobres \\ num clamor de enxadas \\ conquistando a terra. \\ Quero ouvir a dança \\ das aldeias novas \\ nas antigas flautas \\ acordando o mundo. \\ Toda minha sede, \\ cuia de silêncio, \\ beba em vosso canto \\ o Araguaia novo, \\ luta nas enchentes, \\ festa no banzeiro, \\ Povo, Povo, Povo!
}

Tem-se, aqui mais uma vez, a imagem do rio que permeia, inunda, enche o poema, mas, dessa vez, sem força da correnteza, mas com o ritmo contido e repetido do banzeiro. Marcado pela réstia melódica do poema que integra o texto: Povo, Povo, Povo! (2006, p. 19).

Esse é o som do banzeiro que vai e vem numa mesma pronúncia e sempre exata, repetidas vezes. O tom melódico do poema, expresso por meio das rimas simples e átonas, cria um poema-balada. O silêncio de contemplação diante do povo, da natureza, de toda a região, atravessa o poema, e revela um outro silêncio.

O movimento de análise aqui descrito já fora desenvolvido em pesquisa sobre a obra da poetisa Marilza Ribeiro (REIS, 2006, p. 39ss) na qual o silêncio presente nos versos revela a perplexidade do autor diante da atual conjuntura daqueles que sofrem a dominação, e, dessa forma, tem-se o poeta-profeta, que se une ao povo:

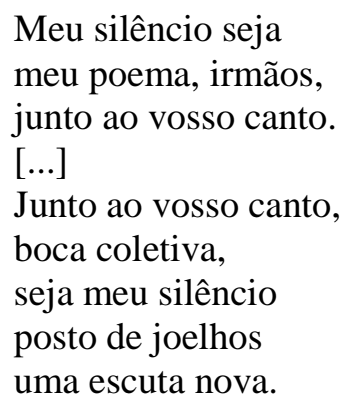

Quero ouvir o Povo! (2006, p. 19). 
O silêncio que o poeta transforma em canto, em ação é um silêncio necessário para "ouvir" antes de agir e que vai servir de instrumento de luta, de festa, de vida. Não é um silêncio de se eximir, de se esquivar, mas aquele da escuta em comunhão, da solidariedade e da necessidade:

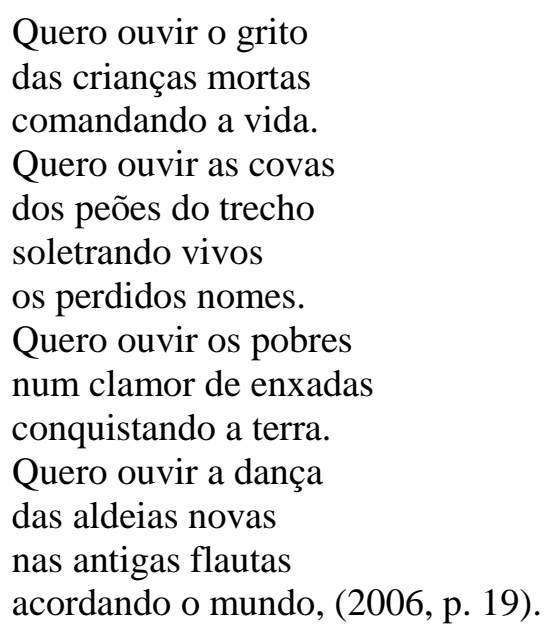

Esse poderia ser o mundo que, no sentindo ontológico e místico, Casaldáliga já conhece, pela apreensão do todo que é o Araguaia e que, seguindo a poética das águas, mantém a elação intrínseca com o rio: "eu e o Araguaia/já nos conhecemos/rios de um só rio/ajeitando o curso/entre Deus e o Povo; (2006, p. 19).

Dessa forma, o poeta participa da vida da região, aqui metaforizado pelo Rio Araguaia e, sobre esse modo de participação, pode-se perceber relação em Cortázar que diz que "a essência da participação consiste, precisamente, em apagar toda dualidade; apesar do princípio de contradição, o sujeito é ao mesmo tempo ele próprio e o ser do qual participa" (CORTÁZAR, 1993, p. 90).

\section{Considerações Finais}

Apresentadas essas análises, colocamos em relevo parte da produção de Casaldáliga, a vocação e empenho para com a mensagem poética e, informações sobre sua luta pela promoção humana, pois, percebemos como ele a plasma na/pela poesia tornando-a comprometida não só com o social, mas também com a cosmologia, tendo em vista que a construção da história humana jamais se dissocia da natureza, pelo contrário, faz surgir um ser humano que com ela tem estreitas relações. 


\section{Referências}

BACHELARD, Gaston. A água e os sonhos: ensaio sobre a imaginação da matéria. Tradução Antônio de Pádua Danesi. São Paulo: Martins Fontes, 1997.

BOSI, Alfredo. Literatura e resistência. São Paulo: Companhia das Letras, 2002.

CANDIDO, Antônio. $O$ estudo analítico do poema. São Paulo: Humanitas Publicações/FFLCH/USP, 1996.

CASAlDALIGA, Pedro. Águas do tempo. Cuiabá: Ed. Amazônia/Fundação Cultural de Mato Grosso, 1989.

Antologia retirante. Rio de Janeiro: Civilização Brasileira, 1978.

Versos adversos. Antologia, de Pedro Casaldáliga. São Paulo: Fundação Perseu Abramo, 2006.

CHEVALIER, Lean. Dicionário de símbolos. Barcelona: Editorial Herder, 1986.

CORTÁZAR, J. Valise de cronópio. 2 ed. São Paulo: Perspectiva, 1993.

COUTO, Mia. Estórias abensonhadas. 7. ed. Lisboa: Editorial Caminho, 2003.

ELIADE, Mircea. Imagens e símbolos. Lisboa: Artes e Letras/Arcádia, 1979.

MAQUÊA, Vera. A imagem saturada de agoras. In: Revista Via Atlântica. São Paulo, n. 21, jul/2012, p. 187-197.

REIS, Célia Maria Domingues da Rocha. Sociedade, erotismo e mito: a poética temporal de Marilza Ribeiro. Cuiabá: EdUFMT, 2006. 